\title{
Structural and Biological Characterization of Two Crotamine Isoforms IV-2 and IV-3 Isolated from the Crotalus durissus cumanensis Venom
}

Luis Alberto Ponce-Soto • Daniel Martins-de-Souza • José Camillo Novello · Sergio Marangoni

Published online: 12 May 2009

(C) Springer Science+Business Media, LLC 2009

Erratum to: Protein J (2007) 26(8):533-540

DOI 10.1007/s10930-007-9094-z

An author's name from this paper incorrectly published as Martins D. It should be Martins-de-Souza D.

The online version of the original article can be found under doi:10.1007/s10930-007-9094-z.

L. A. Ponce-Soto $(\square) \cdot$ D. Martins-de-Souza .

J. C. Novello $\cdot$ S. Marangoni

Departamento de Bioquímica, Instituto de Biologia (IB),

Universidade Estadual de Campinas (UNICAMP), CP 6109,

CEP 13083-970, Campinas, São Paulo, Brazil

e-mail: poncesoto@yahoo.com.ar 